\title{
IMPROVING THE IMPACT STRENGTH OF POLYMER MATRIX COMPOSITE THROUGH THE ADDITIONS OF DIFFERENT ADDITIVES
}

\section{AHMED NAFIE RASHID}

Lecturer, Department of Mechanical Engineering, Mosul University, Nineveh, Iraq

\begin{abstract}
The main objective of this research is to improve the impact strength of polymer matrix composite. This was carried out by using several additives which are Fe particles, Al particles and sawdust particle with different weight percentages $(5 \%, 10 \%$ and $15 \% w t)$, the impact specimens were prepared by using hand-molding method. The results have shown that the impact strength increased with the additives for all samples prepared, also observed that the type of additive and its density played a significant role in the improvement process. Aluminum particles gave uniform distribution through the specimens in addition to other factors. All these helped to give an increase in the results of impact from 2 joule for pure epoxy to 2.5 joule with $5 \%$ wt Al particles to 3 joule for $10 \%$ wt then to 4 joule with $15 \%$ wt Al particle. So the improvement in impact value for the last case was $100 \%$ compared to the pure epoxy.
\end{abstract}

KEYWORDS: Impact Strength, Polymer Matrix Composite, Fe Particle, Al Particles \& Sawdust

Received: Aug 15, 2019; Accepted: Aug 30, 2019; Published: Sep 14, 2019; Paper Id.: IJMPERDOCT201930

\section{INTRODUCTION}

A composite is a structural material that contains two or more combined constituents that are not soluble in each other and combined at a macroscopic level. One constituent is called the matrix phase, which is generally continuous and form the bulk material, the other is the reinforcing phase take the form of particles, fibers and flakes (Kaw, 2006). Particulate filled polymer composites have been used broadly in different fields due to their low producing costs and the ease of manufacturing. Epoxy resins polymers are used widely in composite materials due to their good mechanical, thermal, and electrical properties (Nielsen \& Landel, 1994). There are some polymers characterized by good strength, but their performance is weak when subjected to impact test. Impact test has gained much attention from researchers because there is a danger lies in polymer materials, they may behave ductile under static load but their behaviors change to brittle under the shock stress (Bhatnagar, 2004). The following research focused on studying the impact strength of composite materials and the effect of different additives and some conditions on it.

B. Shivamurthya et al. observed that the result of izod impact test decreases by adding silicon oxide $\left(\mathrm{SiO}_{2}\right)$ particulate filler (Shivamurthya, Siddaramaiahb, \& Prabhuswamyc, 2009). M. A. AL-Nesearawi found that fibers reinforced laminated composite expose better mechanical properties than a reinforced composite the mechanical properties includes (compression strength, impact strength, tensile strength, shear and bending strength, also elasticity modulus) (AL-Nesearawi, 2010). Sanaa A. A. Hafad showed that impact resistance decreased by $16 \%$ with the reinforcement of $50 \mathrm{vf} \%$ sawdust and it was decreased by $43 \%$ after immersion in a salt solution for 60 
days (Sanaa \& Hafad, 2010). Also S. B. Hassan and V. S.Aigbodion found that the impact strength decreased with the reinforcement with eggshell particles to Al-Cu-Mg composite (Hassan \& Aigbodion, 2015). Ibtihal-Al-Namia et al. found that the addition of silica and alumina particles improves the fracture toughness and hardness of the composite materials significantly compare with those of the matrix material (Ibtihal-Al-Namie, Ibrahim, \& Manal Fleyah Hassan, 2011).

Balkees M. Deya'a et al. found that addition of two types of powder $\left(\mathrm{TiO}_{2}, \mathrm{MgO}\right)$ improve the impact strength after immerse on water and chemical solution $(\mathrm{KOH}, \mathrm{HCL})$ with normality $(\mathrm{N}=0.5)$ compared with their values before immersion (Deya'a, Hussien, \& Dway, 2011). Rafah A. Nasif found that there was a decrease in the impact strength values with an increase in the filler loading for all particle sizes (Nasif, 2012). I. M. Dagwa and K. K. Adama observed that the value of impact strength reduced by $24.24 \%$ with the addition of pumice powder to recycle the beverage cans (Dagwa \& Adama, 2018). Finally, I. V. Surendra et al. found the impact strength increased by $33.6 \%$ with the using hybrid fiber reinforced composite than that of sisal fiber reinforced composite (Surendra, Venkateswara Rao, \& Chandu, 2015). In this research different additive materials were used to improve the impact strength of epoxy type (LF-BM).

\section{EXPERIMENTAL WORKS}

\subsection{Raw Materials}

The polymer matrix composite consists of two constituents, the matrix phase materials are generally continuous which are the base materials and the additives which are the reinforced phase. The way of chosen the matrix phase and the reinforced phase is very important because it will affect the properties of the composite. For this reason along investigation have been done to choose the right materials for the polymer matrix composite used in the research.

\section{The Matrix}

The matrix used in this work was Epoxy resin (LF-BM) which is fabricated by (KOSTER). The LF-BM is an epoxy resin with formulated amine hardener and low viscosity component. This type of epoxy has the following properties, mixing volume ratio $(\mathrm{A} / \mathrm{B})$ : $1 / 1, \mathrm{~A}=$ Epoxy resin, $\mathrm{B}=$ the hardener. This resin has cured process (the ability to transform from the liquid state to hard solid at room temperature) much faster at a high temperature.

\subsubsection{The Reinforcement Materials}

Three types of additives were chosen for the improvement of the epoxy, they were iron filing particles of mesh size 48$500 \mu \mathrm{m}$, aluminum particles of size $100 \mu \mathrm{m}$ and sawdust particles of size $355 \mu \mathrm{m}$. The percentages of additives were chosen as 5\%,10\% and 15\% weight percentage. Iron filings one of the most important metallic elements, it is a byproduct of the process of filing and grinding, and characterized by its strength, high hardness and density of $7.8 \mathrm{~g} / \mathrm{cm}^{3}$. Aluminum is one of the ductile metallic elements. Which features lightweight, with a density of one-third of the density of iron $\left(2.7 \mathrm{~g} / \mathrm{cm}^{3}\right)$, non magnetic, ductile besides being easy to machine. Aluminum powder resulting from operations such as turning and milling...etc. Finally sawdust particles characterized by its cheap price because it is a byproduct of fabrications of furniture. As well as the advantage of lightweight, thermal and acoustic insulation quality and density of $\left(0.7 \mathrm{~g} / \mathrm{cm}^{3}\right)$.

\subsection{Preparation of Composite Specimens}

Specimens of composite materials were prepared from the matrix material and the reinforcing materials. The methods of manufacturing composite materials are different each method has its advantage and disadvantages, as well as the appropriate domain which they are applied. 

through the Additions of Different Additive

In this research, the use of hand-molding method in molding returned to its simplicity, easily to apply and to get specimens of different sizes and shapes. The matrix material (epoxy resin) was mixed with reinforcing materials then molded to mold according to suitable shape and size for the further impact test.

\subsection{Experimental Procedure}

The impact test was carried out using the IISO-179 standard for charpy test as in figure 1, four specimens of each case have been tested in order to obtain the best results.

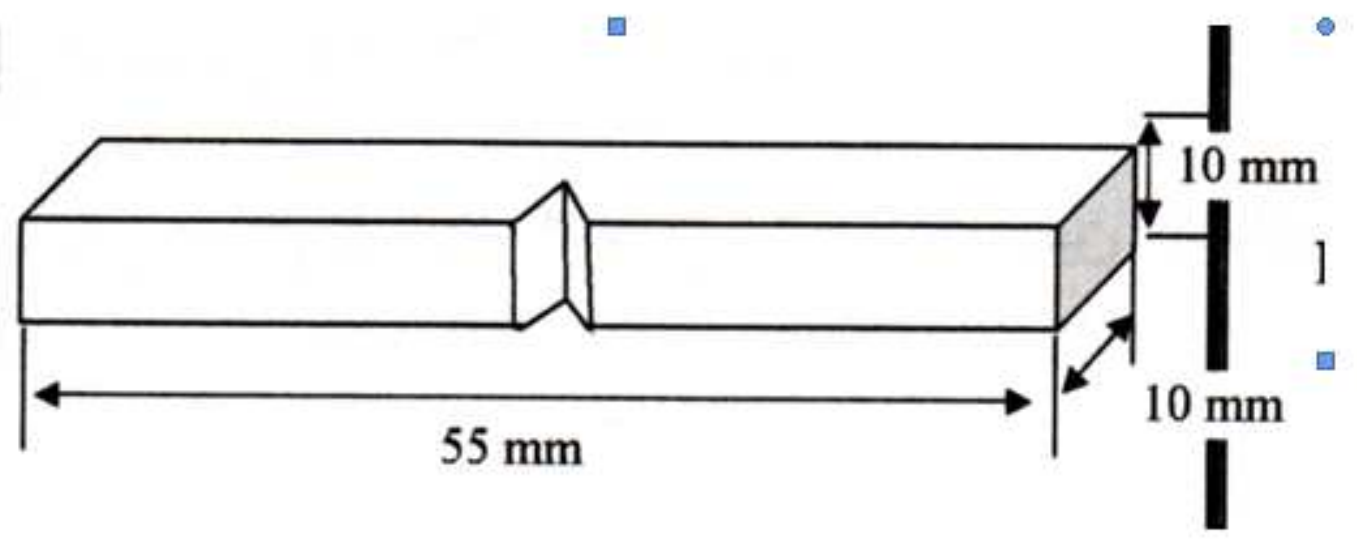

Figure 1: IISO_179 Standard Charpy Test.

The mold used to produce this specimen of impact test is shown in Figure 2. While the impact test was done using the impact test machine (Figure 3).

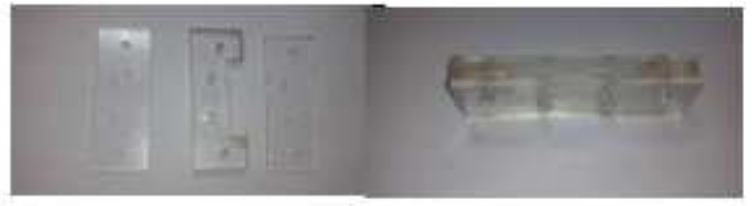

Figure 2: The Mold used for Producing Impact Test Specimen.

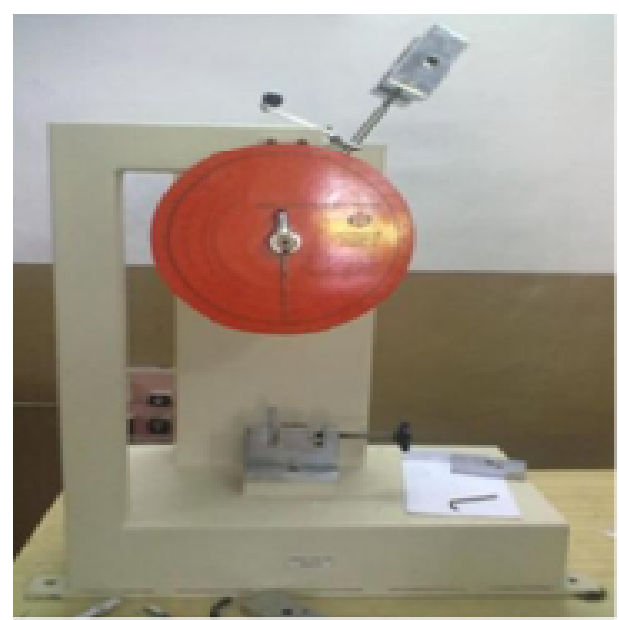

Figure 3: Impact Testing Machine. 


\section{RESULTS AND DISCUSSIONS}

The impact results of the composites fabricated in this research are shown in Figures 4-6, it was found that the impact strength increased in all the cases of the study, but with different rate depending on the density and type of the additives materials. The iron filing (Fe particles) gave small increase with 5\%wt. from 2 to 2.5 joule, then increased to 3 joule with $10 \%, 15 \%$ wt Fe. Despite of the good mechanics of Fe tt did not affect the impact results significantly, due to the higher density of Fe particles $7.8 \mathrm{~g} / \mathrm{cm}^{3}$ ), which le it to precipitate in the base of the specimen with thin layer and did not distribute through the whole specimen.

The opposite happened with sawdust their low density $0.7 \mathrm{~g} / \mathrm{cm}^{3}$ ) gave it the ability to distribute uniformly through the specimens which increase the impact results from 2 to 3 joule for all the percentage despite the poor mechanical properties of sawdust. Finally, the moderate density of aluminum particles which is equal to $2.7 \mathrm{~g} / \mathrm{cm}^{3} \mathrm{gave}$ uniform distribution through the specimens in addition to the good mechanical properties of Al compared with sawdust. All these helped to give an increase in the results of impact from 2 to 2.5 to 3 then to 4 joule.

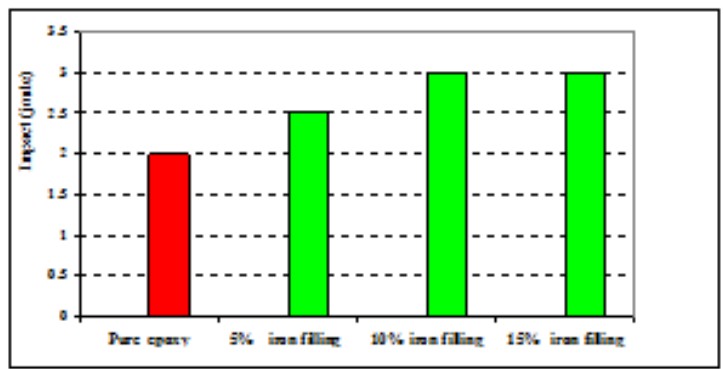

Figure 4: Comparison Between the Impact Tests for Pure Epoxy \& wt.\% of Iron Filing.

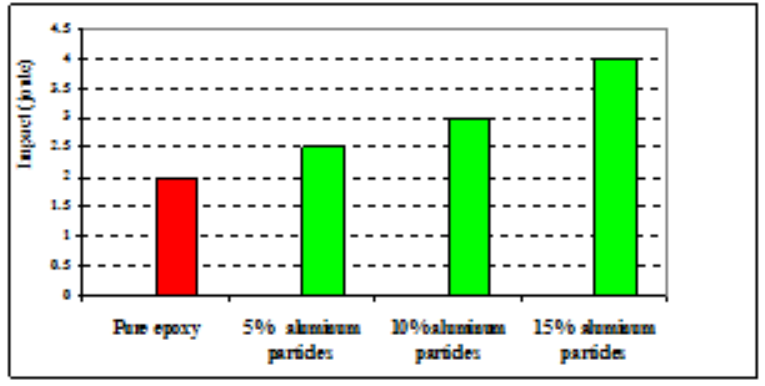

Figure 5: Comparison Between the Impact Tests for Pure Epoxy \& wt.\% of Al Particles.

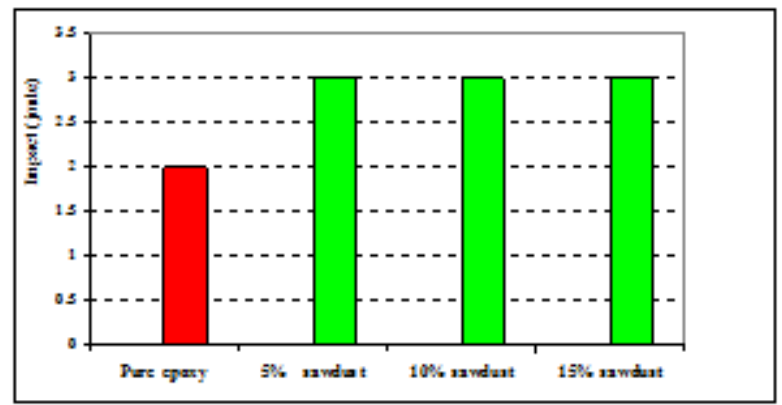

Figure 6: Comparison Between the Impact Tests for Pure Epoxy \& wt.\% of Sawdust. 


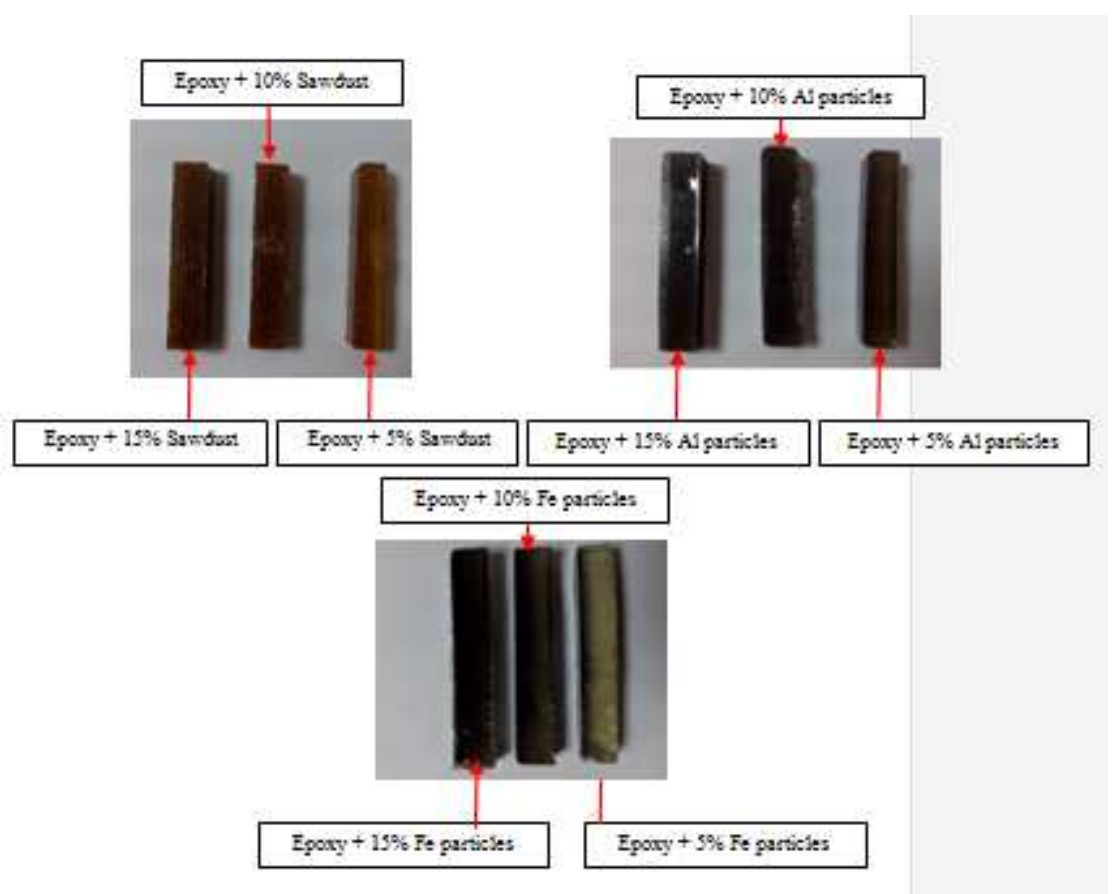

Figure 7: Shows the Effect of the Percentage of the Additives and Density on the their Distribution Through the Specimens.

In the Figure 7, shows the effect of the percentage of the additives and the density on their distribution through the specimens. So, it is clearly noticed that the dense material (Fe particles) precipitate in thin layer near the base and with increasing the percentage of addition from $5 \%$ wt to $(10 \%$ and $15 \% \mathrm{wt}$ ) it began to distribute through the specimens which affected the color of the specimen and its impact strength. While the lighter materials (Al particles and sawdust particles), distribute uniformly through the specimens which improve their impact strength.

Figure 8 represents the side view of the specimens of impact test after fracture. The fracture mode explain the above reality, that the density of particles affected their distribution in the matrix materials, which reflected to the impact results. The specimen to the right contains saw dust which distributed uniformly as can be seen clearly in the figure. So the fracture mode was brittle fracture. While the specimen to the left contains Fe particles which precipitate in the specimen bottom with a thin layer. Hence, the fracture mode was mixed between brittle and ductile fracture. Finally, the specimen in the middle contains aluminum particles gave moderate distribution with brittle and ductile fracture. Also the obtained results in this research were coincided with the results of the researcher (AL-Nesearawi, 2010; Deya'a et al., 2011; IbtihalAl-Namie et al., 2011; Surendra et al., 2015). Several research groups worldwide experimentally found that the ability to reinforce prove effectively by micro particle of metallic or inorganic type for thermoplastic and also thermosetting polymer matrices and improves the mechanical properties. But the improvement relies on filler volume content (Shivamurthya et al., 2009).

The interface quality of the composites, i.e., the static bonding strength as well as the interfacial stiffness, typically plays a very significant role in the materials capability to transmit stresses and elastic deformation from the matrix to the filler. If the filler interaction is poor, the particles are unable to hold any part of the external load, in that situation the strength of the composite decline, this explain the decrease in the impact strength obtained by the researchers in Shivamurthya et al. (2009), Sanaa and Hafad (2010), Hassan and Aigbodion (2015). If the adhesion between the fillers 
and matrix is strong enough, the operant load and deformation transfer occurs between the matrix and filler improves the strength. But another significant fact that, the adhesion between fillers and matrix are more related to the dispersal state of the particles and the load in the matrix phase and this explains how low mechanical properties materials like sawdust gave good impact results.

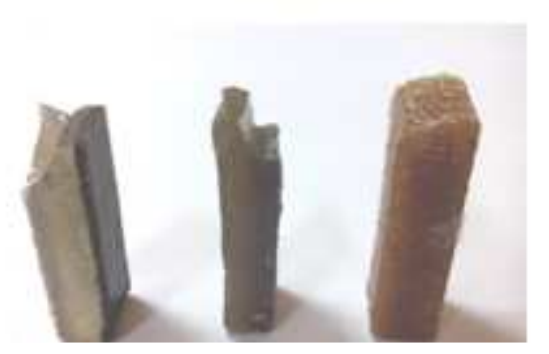

Figure 8: Side View of the Impact Specimens with Different Additive after Fracture.

\section{CONCLUSIONS}

- It is possible to improve the impact strength of the epoxy type (LF-BM) by adding particles especially $\mathrm{Al}$ particles.

- Densities of the particles play great roles in affecting the mechanical properties of composites.

- Some materials like sawdust particles despite its poor mechanical properties, but it have good bonding between fillers and matrix more related to the dispersion state of the particles and the load in the matrix phase.

\section{REFERENCES}

1. Autar K. Kaw, (2006). "Mechanics of composite material” 2nd edition, Taylor \& Francis Group, LLC.

2. Nielsen L. E. and Landel R. F., (1994). "Mechanical properties of polymers and composites", 2nd ed. New York: Marcel Dekker, pp. 557

3. Omar, A. A., El-Shennawy, M., \& Ayad, M. (2015). Study of Wear Behavior of as Cast TiC/7075 Composite. International Journal of Mechanical Engineering, 4(4), 45-52.

4. Bhatnagar, M. S. (2004), Chemistry \& Technology of polymers, 3, published by S. Chand \& Company LTD, New Delhi.

5. Balaji, B., Yuvaraj, C., \& Devakumar, M. Optimisation of Welding Process of Composite Chromium-Carbide Based Tubular Electrode For Hardfacing.

6. B. Shivamurthya, Siddaramaiahb and M. S. Prabhuswamyc, 2009. “Influence of SiO2 Fillers on Sliding Wear Resistance and Mechanical Properties of Compression Moulded Glass Epoxy Composites" Journal of Minerals \& Materials Characterization \& Engineering, Vol. 8, No.7, pp 513-530,

7. M. A. AL-Nesearawi, The Mechanical Properties of Laminated Composites Reinforced With Discontinuous and Continuous Different Fibers, Ibn AL- Haitham J. For Pure \& Appl. Sci. Vol. 23 (1) , pp 2010

8. Sanaa A. A. Hafad, Studying Some of Mechanical Properties (sawdust/Un Saturated Polyester) Composite in Salt Solution, Eng. \& Tech. Journal, Vol. 28, No. 16, 2010

9. Mitra, N. S., Doloi, B., \& Bhattacharyya, B. (2014). Analysis of traveling wire electrochemical discharge machining of Hylam based composites by Taguchi method. International Journal of Research in Engineering \& Technology, 2(2), 223-236. 
10. S.B. Hassan and V.S. Aigbodion, Effects of eggshell on the microstructures and properties of Al-Cu-Mg/eggshell particulate composites, Journal of King Saud University - Engineering Sciences Volume 27, Issue 1, January 2015, Pages 49-56

11. Ibtihal-Al-Namie, Ahmed Aladdin Ibrahim and Manal Fleyah Hassan, Study the Mechanical Properties of Epoxy Resin Reinforced With silica (quartz) and Alumina Particles, The Iraqi Journal for Mechanical and Material Engineering, Vol.11, No.3, 2011,pp 486-506

12. Balkees M. Deya'a, Fawziea M. Hussien and Intihah Gatia Dway, Studying the Impact Strength of (Epoxy with TiO2 and $\mathrm{MgO}$ ) Composite, Eng. \& Tech. Journal, Vol. 29 , No.10, 2011.pp 1971-1978.

13. Rafah A. Nasif, Study the Effect of Volume Fraction of Mica with Different Particle Size on the Mechanical and Electrical Properties for Unsaturated Polyester Composites Eng. \& Tech. Journal, Vol.30, No.20, 2012, pp3573-3580

14. Eneh, A. E. (2015). Application of Recycled Plastics and Its Composites in the Built Environment. Best International Journal of Management, Information Technology and Engineering, 3(3), 9-16.

15. I. M. Dagwa and K. K. Adama, Property evaluation of pumice particulate-reinforcement in recycled beverage cans for AlMMCs manufacture, Journal of King Saud University - Engineering Sciences, Volume 30, Issue 1, January 2018, Pages 61-67

16. I.V. Surendra, K. Venkateswara Rao, K. V. P.P. Chandu, Fabrication and Investigation of Mechanical Properties of Sisal, Jute \& Okra Natural Fiber Reinforced Hybrid Polymer Composites, International Journal of Engineering Trends and Technology (IJETT) - Vol. 19 No. 2 (2015),pp 116-120. 
